\title{
Assessment of Sexual Maturation Among Girls With Special Needs in Tehran, Iran
}

\author{
Hosein Shabani Mirzaee, ${ }^{1}$ Asieh Mosallanejad,, ${ }^{2,}$ Ali Rabbani, ${ }^{3}$ Aria Setoodeh, ${ }^{3}$ Farzaneh Abbasi, ${ }^{3}$ \\ Fatemeh Sayarifard, ${ }^{3}$ and Amir Hosein Memari $^{4}$ \\ ${ }^{1}$ Department of Pediatric Endocrinology, Bahrami Hospital, Tehran University of Medical Sciences, Tehran, IR Iran \\ ${ }^{2}$ Imam Hossein Medical Center, Shahid Beheshti University of Medical Sciences, Tehran, IR Iran \\ ${ }^{3}$ Growth and Development Research Center, Tehran University of Medical Science, Tehran, IR Iran \\ ${ }^{4}$ Sports Medicine Research Center, Tehran University of Medical Sciences, Tehran, IR Iran \\ "Corresponding author: Asieh Mosallanejad, Imam Hossein Medical Center, Shahid Beheshti University of Medical Sciences, Tehran, IR Iran. Tel: +98-217343000. E-mail: \\ mosalladr@gmail.com
}

Received 2016 January 29; Revised 2016 May 07; Accepted 2016 June 04.

\begin{abstract}
Background: There is limited data on sexual maturation among girls with intellectual, sensory, or physical disabilities.

Objectives: The present cross-sectional study was conducted to assess the sexual maturation of girls with these disabilities in special schools.

Methods: In this cross-sectional study, we evaluated the onset and progression of sexual maturation in 642 six to 18 -year-old girls with intellectual, sensory, or physical disabilities from special schools in Tehran. The participants were selected by multi-stage random sampling. Pubertal stages were assessed by visual inspection and palpation based on the rating scales of Tanner. Stage two (breast budding and pubic hair growth) and stage five were considered the onset and end of puberty, respectively.

Results: The mean ages of onset of puberty indicated by breast budding (B2 stage) and by pubic hair growth (P2 stage) were $10.8 \pm$ 1.48 and $10.79 \pm 1.64$ years, respectively. The process of puberty based on breast budding and pubic hair growth was completed at $15.58 \pm 1.85$ and $15.59 \pm 1.8$ years, respectively. The average height at the onset of puberty (stage B2) among participants was $128 \pm$ $28.79 \mathrm{~cm}$ and the average weight was $8.31 \pm 36.47 \mathrm{~kg}$.

Conclusions: Among our patients, the mean ages of onset of puberty indicated by breast budding (B2 stage) and by pubic hair growth (P2 stage) were $10.8 \pm 1.48$ and $10.79 \pm 1.64$ years, respectively. Compared to the data from healthy Iranian girls, our findings indicate that the mean age of pubertal onset among schoolgirls with disabilities is slightly higher than that of their healthy counterparts.
\end{abstract}

Keywords: Sexual Maturation, Girls, Neurodevelopmental Disability, Iran

\section{Background}

Causes of mental disability or intellectual disability and sensory and physical-motor problems among children are very diverse. The most common known cause is chromosomal abnormalities. Birth and neonatal morbidities, preterm birth, and environmental factors are some other causes. In many cases, the cause remains unidentified (1, 2).

Genetic background, geographical location, nutritional status, environmental factors, and diseases play an important role in the growth and maturation of children and adolescents $(3,4)$. In several studies, differences in the age of the onset of puberty have been observed $(5,6)$. In a recent study, Rabbani et al. studied 7,493 healthy, six to 20year-old females from Iran and observed that the average age for the onset of puberty among Iranian females (mean 10.1 years) was similar to most other reported outcomes (4).

Maturity studies for children with mental disabilities and those with sensory and cognitive impairments are limited. In a study of 207 children with cerebral palsy disorder and moderate to severe motor impairment, Worley et al. indicated that the age of onset of breast development was similar to that of the general population, but the process takes longer to complete (7). In a study by Siddiqi et al. (8) between 1987 and 1997 on 15,719 patients with neurodevelopmental disabilities, the patients were at higher risk of precocious puberty than healthy children. In 2006, Cento et al. (9) reported the response of gonadotropins to injections of GnRH in 56 mentally retarded and 146 healthy girls and observed that FSH secretion was lower in the early stages of puberty in girls with intellectual disability. 
In 2014, Baidwan et al. studied the pattern of growth and sexual maturation in 10010 - 20-year-old mentally disabled patients and the same number of healthy females. In their study, pubic hair and breast development in patients happened earlier compared to healthy individuals, but sexual development was delayed during adolescence (15 - 17 years). Physical maturity was also delayed, and patients in all age groups had shorter stature (10).

A reliable estimation of the age of sexual maturity in patients with disabilities allows us to predict their physical and behavioral changes and prepare for the necessary measures in terms of their social relationships. With the knowledge of normal puberty age, we can define precocious or late puberty. The timely detection of early and late sexual maturity also helps in the treatment of these problems.

\section{Objectives}

As far as we know, there are no studies regarding the age of puberty in Iranian females with disabilities, so the present cross-sectional study was conducted in Tehran to evaluate the average age of sexual maturity in these patients. This will help establish a standard for the evaluation of sexual maturation in this group of patients.

\section{Methods}

This cross-sectional study was conducted from 2012 to 2013 on 756 individuals to evaluate the stages of puberty among six to 18-year-old females from Tehran special schools for children with intellectual, sensory, or physical disabilities. In Iran, special schools are categorized based on the form of disability: intellectual disabilities, physicalmotor disabilities, behavioral disorders, sensory (hearing or visual) problems, and multi-faceted disabilities. This study was approved by the ethics committee of Tehran University of Medical Sciences. Multi-stage random sampling was conducted. In this study, 756 students from 12 schools distributed among five regions (north, south, east, west, and central Tehran) were included.

The inclusion criteria were female children and adolescents between six and 18 years old with physical-motor, sensory, or intellectual disabilities. The exclusion criteria were children who were not Iranians or showed sexual ambiguity.

The study was explained in a joint meeting of parents and children, and verbal consent was obtained for each patient. A registration form for each child was filed, which included demographic information from their educational files.

Weight was measured using a Seca scale (Germany), and height was measured with each patient lying on the bed with legs straight and ankles in the anatomical position ( $0^{\circ}$ of dorsiflexion).

BMI was calculated using the following formula: (weight) $\mathrm{kg} /$ (height) $\mathrm{m}^{2}$. The signs of the onset of puberty and its stages were determined by a single female physician based on observation and examination. The Tanner classification system was used to determine the pubertal stages (11). According to this classification system, there are five stages in the course of female puberty. Breast bud growth (thelarche) is usually the first sign of puberty in females (3). In the present study, the B2 level in the Tanner classification was considered as the onset of puberty.

\section{Results}

Overall, 756 individuals were enrolled in the present study. Of the 756 cases, 114 participants were excluded due to lack of cooperation. At the end, 642 six to 18-year-old girls completed the study. The average ages at the onset of puberty in participants based on B2 and P2 levels in the Tanner classification were $10.8 \pm 1.48$ years and $10.79 \pm 1.64$ years, respectively.

The average ages for different stages of breast development based on the Tanner classification are presented in Table 1 . The average age for the start of puberty in girls according to breast bud growth was $10.8 \pm 1.48$ years, and puberty was completed when participants reached a mean age of $15.58 \pm 1.85$ years.

The average ages for different stages of pubic hair growth based on the Tanner classification are presented in Table 2 . The average age for the start of puberty in girls according to pubic hair growth was $10.79 \pm 1.64$ years, and puberty was completed when participants reached a mean age of $15.59 \pm 1.80$ years.

Figure 1 shows the average age of puberty among girls participating in the present study according to breast and pubic hair growth.

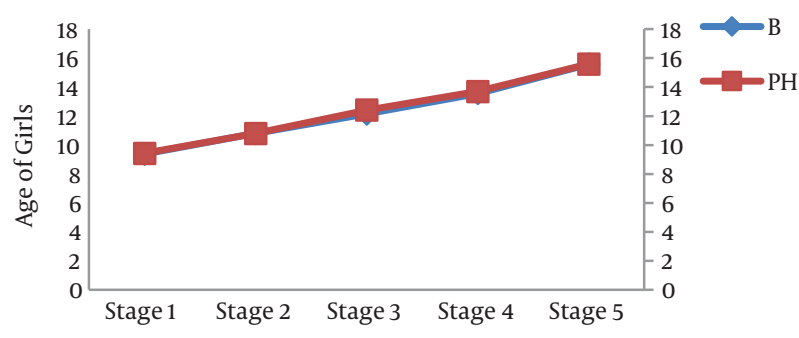

Figure 1. The Average Age of Puberty in Girls Participating in the Present Study According to Breast and Pubic Hair Growth

The average height at the onset of puberty (stage B2) in participants was $128.2 \pm 8.79 \mathrm{~cm}$ and the average weight 
Table 1. The Average age of Participants at Different Stages of Breast Bud Development

\begin{tabular}{|c|c|c|c|}
\hline Stages of Breast Development & No(\%) & Mean \pm SD & 95\% CI \\
\hline B1 & $125(19.4)$ & $9.37 \pm 1.75$ & $9.69-9.05$ \\
\hline B2 & $66(10.3)$ & $10.8 \pm 1.48$ & $11.16-10.44$ \\
\hline B3 & $80(12.4)$ & $12.15 \pm 1.94$ & $12.59-11.71$ \\
\hline B4 & $124(19.3)$ & $13.56 \pm 1.84$ & $13.9-13.22$ \\
\hline B5 & $247(38.4)$ & $15.58 \pm 1.85$ & $15.82-15.34$ \\
\hline
\end{tabular}

Table 2. The Average Age of Participants at Different Stages of Pubic Hair Growth

\begin{tabular}{lccc}
\hline Pubic Hair Growth & No. (\%) & Mean \pm SD & 95\% CI \\
\hline P1 & $119(18.5)$ & $9.42 \pm 1.65$ & $9.72-9.12$ \\
P2 & $87(13.6)$ & $10.79 \pm 1.64$ & $11.15-10.43$ \\
P3 & $62(9.7)$ & $12.40 \pm 2.30$ & $12.98-11.82$ \\
P4 & $140(21.8)$ & $13.69 \pm 1.99$ & $15.03-13.35$ \\
P5 & $234(36.4)$ & 1.80 \\
\hline
\end{tabular}

was $36.47 \pm 8.31 \mathrm{~kg}$ (Table 3 ).

\section{Discussion}

The development of secondary sexual characteristics in adolescents is a sign of normal physiological development $(3,5)$. Therefore, evaluating the onset and progression of the early signs of sexual development and sexual maturation are important in the assessment of individual health. In addition, with the knowledge of normal puberty age, we can define precocious or late puberty (5).

The age for the onset of puberty and secondary sexual characteristics, as well as factors affecting this process, have been discussed in different regions of the world. It has been proven that pubertal onset varies across different populations $(5,12)$. In addition, nutritional status, economic conditions, and disease have a significant impact on the timing of puberty events (13).

In Iran, several studies have been conducted to investigate the age of puberty onset among healthy children and adolescents $(4,5,14)$. In a study on 7,493 healthy Iranian girls, Rabbani et al. (4) found that the mean ages for the start of maturity based on the B2 and P2 stages of maturity according to the Tanner classification were 10.1 and 9.38 years, respectively. In the present study which included 643 female students with intellectual, sensory, or physical disabilities from Tehran the average age for the onset of puberty was 10.8 years based on reaching the B2 stage and 10.79 years based on reaching the P2 stage. These find- ings show a slight delay in puberty compared to the age reported by Rabbani et al. (4) for the healthy population.

Razzaghy et al. (5) have reported the mean age of the onset of puberty for healthy Iranian girls to be 9.74 years based on B2 and 10.49 years based on P2. According to their findings, our patients demonstrate delayed puberty onset compared to the healthy population (4). Similar to our findings, in 1975, Salerno et al. showed that females with intellectual disability show a delay in puberty compared to healthy individuals (15). A similar delay has been reported by Evans et al. (16) in mentally handicapped females.

The delay in puberty in this group of children might be related to eating disorders or the side effects of some medications such as corticosteroids and psychotropic drugs as well as a higher incidence of endocrine diseases (17-19). As a general rule in mental and motor disabilities with genetic and chromosomal origin, impaired development of the neuroendocrine system and the evolution of the GnRH-producing neurons causes a delay of gonadal development, which can cause a delay of puberty (20).

Cento et al. (9) have reported that FSH secretion in response to GnRH treatment in the early stages of puberty was impaired in females with intellectual disability. They concluded that the low sensitivity of cells secreting FSH may be due to dysfunction of catecholaminergic, opioid, or GABAergic routes

In this study, children in different age groups were shorter compared to the healthy peers reported on by Rabbani et al. (4) The average height in the Rabbani et al. study was reported to be $140.3 \mathrm{~cm}$ in the B2 stage, but it was only 
Table 3. The Average Height, Weight, and BMI at Different Stages of Puberty

\begin{tabular}{|c|c|c|c|}
\hline Stages of Breast Development Stages of Pubic Hair & Height $(\mathrm{Cm}) \pm \mathrm{SD}$ & Weight $(\mathrm{Kg}) \pm$ SD & $\mathbf{B M I} \pm \mathbf{S D}$ \\
\hline B1 & $122.33 \pm 11.66$ & $26.65 \pm 12.01$ & $17.83 \pm 8.03$ \\
\hline P1 & $123.59 \pm 11.56$ & $27.94 \pm 10.76$ & $18.40 \pm 6.66$ \\
\hline B2 & $128.2 \pm 8.79$ & $36.47 \pm 8.31$ & $22.19 \pm 4.35$ \\
\hline $\mathbf{P 2}$ & $129.59 \pm 10.97$ & $32.08 \pm 13.13$ & $19.11 \pm 7.29$ \\
\hline P3 & $137.91 \pm 8.87$ & $38.45 \pm 13.12$ & $20.11 \pm 6.10$ \\
\hline B4 & $143.58 \pm 11.01$ & $42.65 \pm 10.18$ & $20.71 \pm 5.21$ \\
\hline P4 & $145.59 \pm 11.05$ & $43.55 \pm 13.68$ & $20.56 \pm 5.53$ \\
\hline B5 & $150.35 \pm 10.79$ & $56.77 \pm 16.95$ & $25.2 \pm 7.19$ \\
\hline P5 & $151.44 \pm 10.90$ & $58.38 \pm 16.76$ & $25.52 \pm 7.24$ \\
\hline
\end{tabular}

$128.2 \mathrm{~cm}$ among our participants. Previous studies on patients with intellectual disability in Tehran indicate similar findings (21). This is similar to a finding of Baidwan et al. (17) on patients with intellectual disability from India (10). Although eating disorders can be considered as the cause of this finding, associated endocrine disorders such as GH-IGF1 axis dysfunction, thyroid disorders, and other unknown conditions should be considered. This explains the fact that in the Baidwan et al. study, despite the elimination of eating disorders as a factor, short stature was still present. In 2009, Kuperminc et al. (17) studied 20 six to 18-year-old patients with cerebral palsy for three years and compared them to a group of 63 healthy children in terms of growth before and during puberty. Children with cerebral palsy were behind in all stages of their growth compared to healthy controls. This study indicated a defect in the GH-IGF1 axis among patients.

The present study had some shortcomings. For example, due to a lack of access to the medical records of children, we could not divide our participants based on the type of underlying disease (cerebral palsy, Down syndrome, etc.); therefore, the cause of intellectual disability was not identified. In addition, we had no control group in this study, which might limit the reliability of our results.

\subsection{Conclusion}

In our patients, the mean ages of onset of puberty indicated by breast budding (B2 stage) and by pubic hair growth (P2 stage) were $10.8 \pm 1.48$ years and $10.79 \pm 1.64$ years, respectively. Compared to the data from healthy Iranian girls, our findings indicate that the mean age of pubertal onset in schoolgirls with disabilities is slightly higher than that of their healthy counterparts.

\section{Acknowledgments}

We would like to thank the participants and their families for participating in this study. We also thank the Tehran department of education for their valuable help, and we are also obliged to the clinical research development unit at the Imam Hossein medical and educational center in Tehran.

\section{References}

1. Rauch A, Hoyer J, Guth S, Zweier C, Kraus C, Becker C, et al. Diag nostic yield of various genetic approaches in patients with unexplained developmental delay or mental retardation. Am J Med Genet A 2006;140(19):2063-74. doi:10.1002/ajmg.a.31416. [PubMed: 16917849].

2. Morano JP. Sexual Abuse of the Mentally Retarded Patient: Medical and Legal Analysis for the Primary Care Physician. Prim Care Companion J Clin Psychiatry. 2001;3(3):126-35. [PubMed: 15014610].

3. Mul D, Fredriks AM, van Buuren S, Oostdijk W, Verloove-Vanhorick SP, Wit JM. Pubertal development in The Netherlands 1965-1997. Pediatr Res. 2001;50(4):479-86. doi: 10.1203/00006450-200110000-00010. [PubMed: 11568291].

4. Rabbani A, Motlagh ME, Mohammad K, Ardalan G, Maftoon F, Shahryari S, et al. Assessment of pubertal development in Iranian girls. Iran J Pediatr. 2010;20(2):160-6. [PubMed: 23056698].

5. Razzaghy-Azar M, Moghimi A, Sadigh N, Montazer M, Golnari P, Zahedi-Shoolami L, et al. Age of puberty in Iranian girls living in Tehran. Ann Hum Biol. 2006;33(5-6):628-33. [PubMed: 17381060].

6. Kashani HH, Kavosh MS, Keshteli AH, Montazer M, Rostampour N, Kelishadi R, et al. Age of puberty in a representative sample of Iranian girls. World J Pediatr. 2009;5(2):132-5. doi: 10.1007/s12519-009-0026-1. [PubMed: 19718536].

7. Worley G, Houlihan CM, Herman-Giddens ME, O'Donnell ME, Conaway M, Stallings VA, et al. Secondary sexual characteristics in children with cerebral palsy and moderate to severe motor impairment: a cross-sectional survey. Pediatrics. 2002;110(5):897-902. [PubMed: 12415027].

8. Siddiqi SU, Van Dyke DC, Donohoue P, McBrien DM. Premature sexual development in individuals with neurodevelopmental disabilities. Dev Med Child Neurol. 1999;41(6):392-5. [PubMed:10400173]. 
9. Cento RM, Ciampelli M, Proto C, Le Donne M, Romano C, Lanzone A. Neuroendocrine features of pubertal development in females with mental retardation. Gynecol Endocrinol. 2001;15(3):178-83. [PubMed 11447728].

10. Baidwan S, Paul MM, Chhatwal J, Deswal R. Growth and sexual maturity pattern of girls with mental retardation. Int J Appl Basic Med Res. 2014;4(1):38-42. doi: 10.4103/2229-516X.125691. [PubMed: 24600577].

11. Marshall WA, Tanner JM. Variations in pattern of pubertal changes in girls. Arch Dis Child. 1969;44(235):291-303. [PubMed: 5785179].

12. Motlagh ME, Rabbani A, Kelishadi R, Mirmoghtadaee P, Shahryari S, Ardalan $\mathrm{G}$, et al. Timing of puberty in Iranian girls according to their living area: a national study. J Res Med Sci. 2011;16(3):276-81. [PubMed: 22091244].

13. Shen T, Habicht JP, Chang Y. Effect of economic reforms on child growth in urban and rural areas of China. $N$ Engl J Med. 1996;335(6):400-6. doi: 10.1056/NEJM199608083350606. [PubMed 8663882].

14. Rabbani A, Khodai S, Mohammad K, Sotoudeh A, Karbakhsh M, Nouri $\mathrm{K}$, et al. Pubertal development in a random sample of 4,020 urban Iranian girls. J Pediatr Endocrinol Metab. 2008;21(7):681-7. [PubMed: 18780603].

15. Salerno LJ, Park JK, Giannini MJ. Reproductive capacity of the mentally retarded.J Reprod Med. 1975;14(3):123-9. [PubMed:165294]
16. Evans AL, McKinlay IA. Sexual maturation in girls with severe mental handicap. Child Care Health Dev. 1988;14(1):59-69. [PubMed: 2966014].

17. Kuperminc MN, Gurka MJ, Houlihan CM, Henderson RC, Roemmich JN, Rogol AD, et al. Puberty, statural growth, and growth hormone release in children with cerebral palsy. J Pediatr Rehabil Med. 2009;2(2):131-41. doi: 10.3233/PRM-2009-0072. [PubMed: 20216931].

18. Memari A, Ziaee V, Mirfazeli F, Kordi R. Investigation of autism comorbidities and associations in a school-based community sample. J Child Adolesc Psychiatr Nurs. 2012;25(2):84-90. doi: 10.1111/j.17446171.2012.00325.x. [PubMed: 22512525].

19. Memari AH, Ziaee V, Beygi S, Moshayedi P, Mirfazeli FS. Overuse of psychotropic medications among children and adolescents with autism spectrum disorders: perspective from a developing country. Res Dev Disabil. 2012;33(2):563-9. doi: 10.1016/j.ridd.2011.10.001. [PubMed: 22119705].

20. Van G, Dooren LJ. Studies in Oligophrenia. Iii. Somatosexual Maturation in Mentally Deficient Children. Acta Paediatr. 1963;52:557-63. [PubMed: 14082583].

21. Memari AH, Kordi R, Ziaee V, Mirfazeli F, Setoodeh MS. Weight status in Iranian children with autism spectrum disorders: Investigation of underweight, overweight and obesity. Res Autism Spect Dis. 2012;6(1):234-9. 